\title{
Accuracy of direct magnetic resonance arthrography in the diagnosis of triangular fibrocartilage complex tears of the wrist
}

\author{
Suraj Joshy $•$ Kenneth Lee $\cdot$ Subodh C. Deshmukh
}

Received: 10 September 2006 /Revised: 18 November 2006 / Accepted: 20 November 2006/Published online: 11 January 2007

(C) Springer-Verlag 2007

\begin{abstract}
The aim of this study was to assess the value of direct magnetic resonance (MR) arthrography of the wrist for detecting full-thickness tears of the triangular fibrocartilage complex (TFCC). Twenty-four consecutive patients who had ulnar-sided wrist pain and clinical suspicion of TFCC tear were included in the study. All patients underwent direct MR arthrography and then wrist arthroscopy, and the results of MR arthrography were compared with the arthroscopic findings. The positive predictive value of MR arthrography in detecting TFCC full-thickness tear was 0.95 , and the negative predictive value was 0.50 . The sensitivity of MR arthrography in detecting a TFCC full-thickness tear was $74 \%(15 / 19)$, and specificity was $80 \%(4 / 5)$. The overall accuracy of MR arthrography in detecting a full-thickness tear of the TFCC in our study was $79 \%(19 / 24)$. We believe that diagnosis of tears in the TFCC by direct MR arthrography is not entirely satisfactory, although MR arthrography has a high positive predictive value for detecting TFCC tears. Negative results of MR arthrography in patients with clinical suspicion of TFCC tear should be interpreted with caution.
\end{abstract}

Résumé Le but de cette étude est d'évaluer la valeur de l'arthro IRM du poignet don't le diagnostic est rupture complète du ligament triangulaire (TFCC). Une série continue de 24 patients qui avaient des douleurs du bord

S. Joshy $(\bowtie) \cdot$ S. C. Deshmukh

Department of Orthopaedics, City Hospital,

Birmingham, UK

e-mail: surajjoshy@yahoo.co.uk

K. Lee

Department of Radiology, City Hospital,

Birmingham, UK ulmaire du poignet et une suspicion clinique de lésions du TFCC ont été inclus dans la série. Tous les patients ont eu une arthro IRM et ensuite une arthroscopie du poignet. Les résultats de l'arthro IRM ont été comparés avec les constatations arthroscopiques. La valeur prédictive positive de l'arthro IRM dans la détection des ruptures complètes du TFCC était de 0,95 et la valeur prédictive négative était de 0,50. La sensibilité de l'arthro IRM dans la détection des ruptures complètes du TFCC étaient de 74\% (15/19) et la spécificité était de $80 \%(4 / 5)$. La capacité globale de l'arthro IRM dans la détection des ruptures complètes du TFCC dans notre étude était de 79\% (19/24). Nous pensons que le diagnostic des ruptures du TFCC par arthro IRM n'est pas complètement satisfaisant bien que cet examen ait une valeur prédictive positive élevée dans la détection de ces lésions. Une arthro IRM négative, chez un patient qui présente une suspicion clinique de rupture du TFCC doit être interprétée avec précaution.

\section{Introduction}

Triangular fibrocartilage complex (TFCC) tear is a common cause for pain and instability in the wrist $[11,13]$. Tears of the TFCC may not be apparent on clinical examination alone, and a variety of radiographic tools have been used to enhance the accuracy of diagnosis [11, 13]. Arthrography of the wrist has been shown to be effective in diagnosing TFCC tears [1]. Magnetic resonance imaging (MRI) is a useful tool in the imaging of the wrist because of its superior soft-tissue contrast and multiplanar capability, but it has received less attention [1, 11, 13]. Combining MRI with arthrography could potentially increase the accuracy. The aim of our study was to assess the accuracy of direct 
MR arthrography in detecting full-thickness TFCC tears of the wrist.

\section{Patients and methods}

We evaluated 24 consecutive patients who underwent MR arthrography of the wrist for suspected TFCC tear over a period of 3 years between November 2002 and November 2005. Patients were selected for MR arthrography and arthroscopy based on an experienced hand surgeon's clinical suspicion of TFCC tear. Arthroscopy was carried out regardless of normal or abnormal MR arthrography findings, and the decision for arthroscopy was based purely on clinical findings. Normal or abnormal MR arthrography findings did not affect the decision to offer arthroscopy in this study.

Thirteen patients were female, and 11 were male. Their mean age was 43 years (range 24-71 years). All patients had chronic ulnar-sided wrist pain. The findings of MR arthrography were compared with the arthroscopic findings, which were considered the gold standard.

All MR arthrographic examinations were carried out after injecting 3-4 $\mathrm{ml}$ of diluted gadolinium (1 in 100 dilution) directly into the lateral radiocarpal joint under direct fluoroscopic control. MR examination was performed with a 1-Tesla Siemens Harmony MR scanner within 30 min of injecting the intra-articular contrast. A multipurpose flexible surface coil was used, and 3-mm slices were taken in three orthogonal planes with the imaging protocol as follows: coronal $\mathrm{T} 1, \mathrm{~T} 1$ fat saturation, proton density fat saturation, sagittal T1 fat saturation, and axial T2 GE. All images were interpreted by a single musculoskeletal radiologist.

TFCC was classified as either torn (a full-thickness tear) or normal. A tear was diagnosed on imaging if there was evidence of disruption of fibres with associated leakage of intra-articular contrast material from the radiocarpal joint into the inferior radio-ulnar joint. TFCC was considered normal on imaging if there was uniform low signal intensity at the radial and ulnar attachments, no central defect, and no area of thinning or increased signal intensity. No attempt was made to differentiate a small partial tear from a normal TFCC. An experienced hand surgeon performed arthroscopy within 7 months of MR arthrography (mean 3.5 months, range 1-7 months). The disc of the TFCC was classified as torn, thinned, or normal on the arthroscopy report. If torn, the tear was classified as central, peripheral, or detached from the sigmoid notch. A thinned TFCC was noted if the trampoline sign was positive (loss of bounce on probing with the arthroscopy hook). Statistical analyses included determining the positive predictive value, negative predictive value, sensitivity, specificity, and accuracy.
Table 1 Results of magnetic resonance (MR) arthrography and arthroscopy

\begin{tabular}{|c|c|c|c|}
\hline \multirow[b]{2}{*}{ MR arthrography } & \multicolumn{3}{|c|}{ Arthroscopy } \\
\hline & & Tear & No tear \\
\hline & Tear & 15 true positives & 1 false positive \\
\hline & No tear & 4 false negatives & 4 true negatives \\
\hline
\end{tabular}

\section{Results}

Sixteen tears of the TFCC were diagnosed by MR arthrography, while arthroscopy revealed tears in 19 patients. Detailed results, including false-positive and false-negative results, are given in Table 1.

The positive predictive value of MR arthrography in detecting TFCC tear was 0.95 , and the negative predictive value was 0.50 . The sensitivity of MR arthrography in detecting TFCC tear was $74 \%(15 / 19)$, and specificity was $80 \%(4 / 5)$. The overall accuracy of MR arthrography in detecting TFCC tear in our study was 79\% (19/24). Arthroscopy also revealed thinning of the TFCC (no tear) in one patient in whom MR arthrography showed a normal appearance. In five out of 24 cases, there was disagreement between the arthroscopic and MR arthrographic findings. In four patients, MR arthrography failed to detect a tear, although arthroscopy revealed a tear (false negatives). Review of the scans was done by the radiologist, and this revealed no full tears. In one patient, MR arthrography picked up a tear that was not seen on arthroscopy. This patient had evidence of scapholunate dissociation on arthroscopy. Review of the scan showed a tear with typical contrast leakage into the inferior radio-ulnar joint.

\section{Discussion}

Arthrography of the wrist has historically been the standard imaging modality for suspected TFCC tear $[6,8,13]$. However, arthrography neither permits the exact localisation of the tear nor provides information about the adjacent soft tissue and bony structures [11]. Combining MRI with direct arthrography could potentially enhance the accuracy of the diagnosis. There is a paucity of studies in the English literature that look specifically at the diagnostic accuracy of direct MR arthrography of the wrist in detecting TFCC tears.

The reported sensitivity and specificity of plain MRI for diagnosing TFCC tear vary widely, between $44 \%$ and $100 \%$ [1-3, 5, 9-13]. This range could be partly due to wide variations in practice, such as the resolution of the scanner used, the thickness of the sections used, the use of 
dedicated surface coil, and the radiologist's experience. Indirect MR arthrography has also been used in diagnosing TFCC tears. Herold et al. reported a sensitivity of $100 \%$, specificity of $77 \%$, and accuracy of $93 \%$ in their series of 45 patients who had indirect MR arthrography [4]. However, in their study the MR arthrograms were evaluated by two radiologists using a consensus score. Haims et al. reported a sensitivity of $67 \%$, specificity of $87 \%$, and accuracy of $78 \%$ in a recent study of 41 indirect MR arthrography examinations [3]. The methods used in their study were close to ours, although the scanner used was 1.5 Tesla. Meier et al. reported a sensitivity of $94 \%$, specificity of $89 \%$, and accuracy of $94 \%$ in their large series of 125 patients who underwent direct MR arthrography [7]. The positive and negative predictive value in their series was $91 \%$ and $93 \%$, respectively [7]. These results could be partially due to the high number of cases done in their unit and higher resolution of the scanner.

In our study we used a standard 1-Tesla scanner, a multipurpose flexible surface coil, and 3-mm sections. All of the scans were reported by an experienced musculoskeletal radiologist. The sensitivity, specificity, and accuracy in our study were $74 \%, 80 \%$, and $79 \%$, respectively, and are lower than a previous reported study of direct MR arthrography [7]. In our study MR arthrography had a high positive predictive value (0.95) for diagnosing a fullthickness TFCC tear, but the negative predictive value was only 0.50 .

A limitation of our study is the small number of patients compared with some of the previous studies. Also, there was an average time gap of 3.5 months between the MR arthrography and the arthroscopy. This gap could be a potential source of error if patients had any subsequent injury to the wrist.

We believe that diagnosis of tears in the TFCC by direct MR arthrography is not entirely satisfactory. However, MR arthrography has a high positive predictive value for detecting TFCC tears. Negative results of MR arthrography in patients with clinical suspicion of TFCC tear should be interpreted with caution.

\section{References}

1. Cerofolini E, Luchetti R, Pederzenni L et al (1990) MR evaluation of triangular fibrocartilage complex tears in the wrist: comparison with arthrography and arthroscopy. J Comput Assist Tomog 14:963-967

2. Golimbu CN, Firooznia H, Melone CP Jr et al (1989) Tears of the triangular fibro cartilage of the wrist: MR imaging. Radiology 173:731-733

3. Haims AH, Schweitzer ME, Morrison WB et al (2003) Internal derangement of the wrist: indirect MR arthrography versus unenhanced imaging. Radiology 227:701-707

4. Herold T, Lenhart M, Held P et al (2001) Indirect arthrography of the wrist in the diagnosis of TFCC lesions. Rofo 173(11):10061011

5. Kato H, Nakumara R, Shinoya K et al (2001) Does highresolution MR imaging have better accuracy than standard MR imaging for evaluation of the triangular fibro cartilage complex. $\mathrm{J}$ Hand Surg [Br] 26(5):502-503

6. Levisohn EM, Rosen ID, Palmer AK (1991) Wrist arthrography: value of the three compartment injection method. Radiology 179:231-239

7. Meier R, Schmitt R, Krimmer H (2005) Wrist lesions in MRI arthrography compared with wrist arthroscopy. Handchir Mikeochir Plast Chir 37(2):85-89

8. Metz VM, Mann FA, Gilula LA (1993) Three compartment wrist arthrography: correlation of the pain site with location of uni- and bidirectional communications. Am J Roentgenol 160:819-822

9. Morley J, Bidwell J, Bransby-Zachary M (2001) A comparison of the findings of wrist arthroscopy and magnetic resonance imaging in the investigation of wrist pain. J Hand Surg [Br] 26(6):544-546

10. Pederzini L, Luchetti R, Soragni O et al (1992) Evaluation of the triangular fibro cartilage complex tears by arthroscopy, arthrography and magnetic resonance imaging. Arthroscopy 8:191-197

11. Potter HG, Asnis-Ernberg L, Weiland AJ et al (1997) The utility of high resolution magnetic resonance imaging in the evaluation of triangular fibrocartilage complex of the wrist. J Bone Joint Surg A 79-A:1675-1684

12. Schweitzer ME, Brahme SK, Holder et al (1992) Chronic wrist pain: spin-echo and short tau inversion recovery MR imaging and conventional MR arthrography. Radiology 182:205-211

13. Zlatkin MB, Chao PC, Osterman AL et al (1989) Chronic wrist pain: MR imaging. Radiology 173:723-729

Further reading

1. Grissom LE, Harcke HT (1997) Ultrasonography of nondevelopmental dysplasia of the hips. Pediatr Radiol 27:70-74 